\title{
ONTARIO CRIPPLED CHILDREN'S CENTRE TISSUE TRAUMA PROGRAMME
}

\author{
By George Hahn, M.D., F.R.C.P.(C)Paed., F.R.C.P.(C)P.M.R., and \\ RoBIN Black, B.Sc., B.A.Sc., P.Eng. \\ Departments of Medicine and Rehabilitation Engineering, Ontario Crippled Children's \\ Centre, 350 Rumsey Road, Toronto, Ontario M4G IR8, Canada
}

Abstract. In a large paediatric rehabilitation centre a team approach has been taken to formulate policy, to provide service and to do research with respect to the common and costly problem of tissue trauma. In our young population the commonest decubiti result from wheelchair sitting.

This paper describes the service programme and research endeavours.

Key words: Tissue trauma; Paediatrics.

\section{Introduction}

THE goal is prevention of tissue trauma.

Our patients are in the paediatric and young adult age-group. Many more of our patients have a congenital rather than an acquired cause for their insensitive skin.

Most of the tissue trauma seen arises from wheelchair sitting. Orthotic and shoe problems account for the remaining trauma.

Two years ago a team rehabilitation approach was taken to the problem of decubitus care and prevention. A Tissue Trauma Committee with representation from medicine, surgery, rehabilitation engineering, nursing and therapy has met regularly to decide on policy particularly with respect to both service and research programmes.

\section{Service Programme}

\section{Methods}

A programme coordinator, a member of the nursing department, was appointed. The coordinator's duties have been to establish a separate file for each in- and out-patient seen, and to include all these files in a Central Tissue Trauma Case Registry. Each patient's file includes a condensed assessment sheet on the front of which the main historical, medical, orthopedic, urologic, orthotic, cutaneous and socio-psychologic parameters are captured. On the back of this sheet are diagrams on which one can sketch the important skeletal deformities such as pelvic obliquity, scoliosis, kyphosis, hip and knee range of movement. One can also indicate sites of previous and current scars and decubiti. Lastly, one can diagrammatically indicate the excessive or unbalanced forces over bony prominences. Along with the assessment sheet each file has a dermatome sheet on which cutaneous innervation can be diagrammatically shown. The coordinator is also responsible for assuring that excellent clinical photographs are taken in the visual education department under conditions of good lighting and under standardised photographic technique. The camera has a grid to assure constant distance between lesion and lens. Each photograph is identified by patient number and 


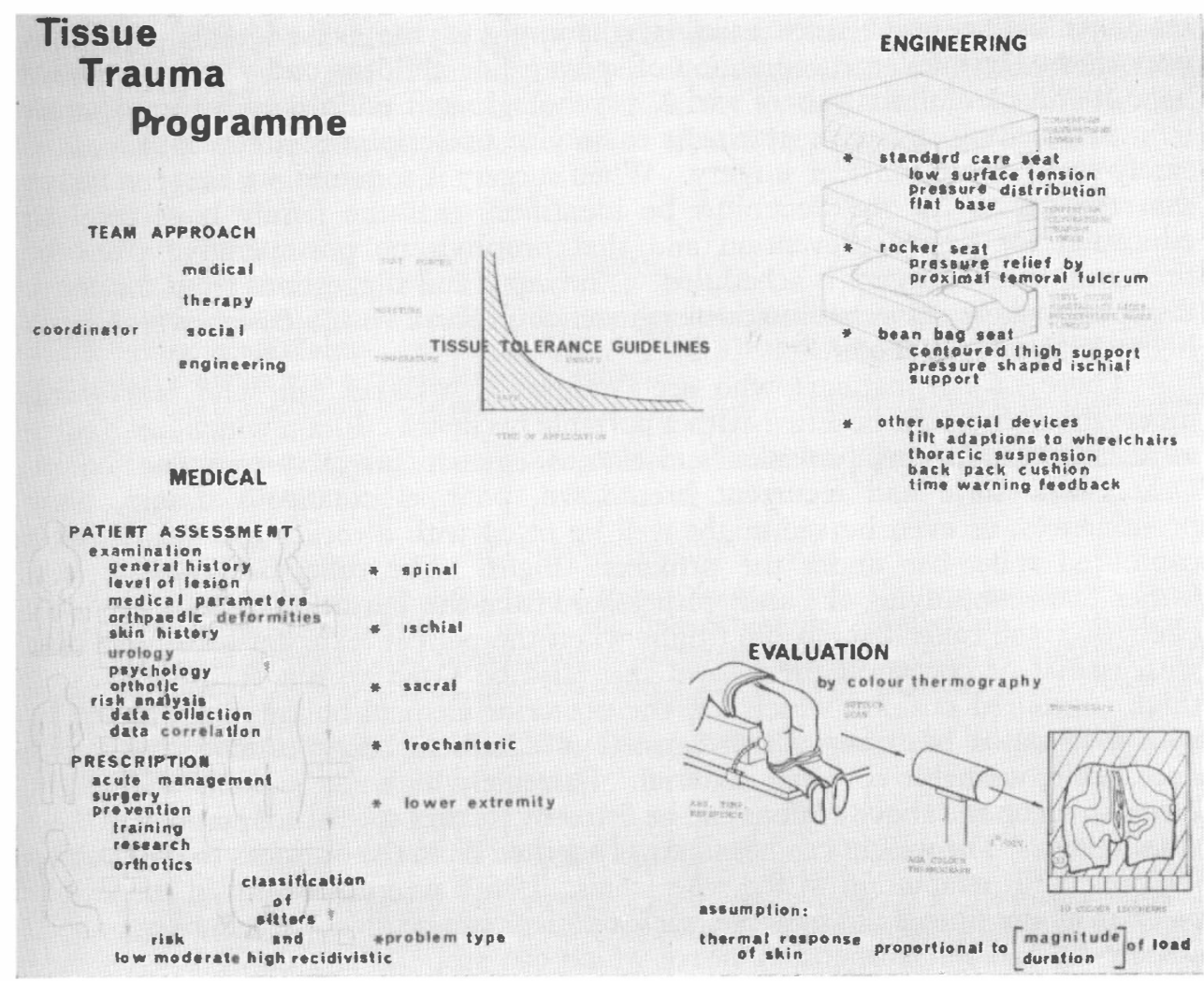

FIG. I

date taken. Photographs are taken at appropriate times and add a valuable parameter to the record. The file contains all tissue trauma consultant notes and follow-up notes. Lastly, the engineer provides a detailed description of the final devices fitted. The Central Registry thus becomes not only a service tool but will become a research aid.

In-patients who have current tissue trauma are seen once weekly on Ulcer Management Rounds by the in-house medical, nursing and therapy staff and fortunately these disciplines are joined by our Rehabilitation Engineer. The actual care for healing tissues is very standard. The emphasis at these rounds has shifted more and more toward potential problem recognition. Preventative orthotic prescriptions with respect to wheelchair seats, backrests and cushions are therefore discussed and appropriate prescriptions are written in the hope that the children by sitting on these provisions will not break down their skin in future years. We believe that slung wheelchair seats should be avoided and replaced by a standard care seat. At this Clinic a glass table examination is used to visualise buttock pressure distribution. Lastly, in these Rounds, patients with high risk, recurrent tissue breakdown, and unfortunately the rare recidivistic patient are all identified to be reviewed in more depth at the weekly Tissue Trauma Clinic held two days later.

The Tissue Trauma Clinic is led by our consultant plastic surgeon, attended $\mathrm{I} 5 / \mathrm{I}-\mathrm{G}$ 
by an orthopedic consultant when required, by in-house physiatric staff, and by residents. The input from nursing, therapy and the behavioural sciences is important. In our large population of spina bifida children and young adults we have found careful analysis of social, psychologic and education factors of great help in reaching decisions pertinent to service prescriptions. Fortunately, it is rarely necessary to consider surgery. When surgery is required our surgeon insists that the causes for the decubitus be identified, that the family have received education for future prevention and that prophylactic postoperative plans be prepared, before surgery is scheduled. The input and suggestions from the above disciplines allow our rehabilitation engineer to proceed with a design which has a higher chance for success.

Those of our patients who are community walkers but who lack sacral innervation may well be fitted with a portable backpack cushion which can double as an adequate seating provision and also as a pouch for carrying school-books. Others who have had recurrent breakdown, poor subcutaneous tissues, bony prominences, or even bursae might well be fitted with a rocker seat which has a contoured roller-bar under the proximal thighs. The roller-bar consists of a firmer foam amplifying the shift of pressure from the buttocks, via a teeter-totter effect over the roller-bar, to the thighs when the patient leans forward. Patients with ischial or coccygeal breakdown may also be fitted with a custom-moulded thigh contoured cushion which has the posterior element hollowed out and filled with a so-called bean bag which consists of ethafoam beads contained within a stretchable, washable covering material. Extremely high risk patients who might break down on the above cusions can be fitted by further special adaptations to their wheelchairs. The weight can be effectively shifted from the buttocks to the back by building a tilt adaptation to the wheelchair. If full weight-bearing in the sitting position at any time is not possible, such a patient can be given a vacuum moulded, custom-fit, thoracic suspension sleeve which can suspend any desired percentage of the patient's weight through the wheelchair arms.

\section{Research Endeavours}

Through combined interest and good cooperation the medical personnel and the rehabilitation engineering personnel in one centre can work well together.

For example, biofeedback techniques have been employed in a number of programmes at this Centre, particularly in the Cerebral Palsy Programme. Our engineer has tried this concept particularly for our slightly retarded or less motivated patients. The cushions of the chairs of these patients have been provided with time-warning feedback devices. These experimental units require the patient to accumulate a total lifting or tilting time of one minute in fifteen if they are not to sound off. Furthermore, the device counts and stores the number of lifts, the total sitting time and the accumulated time of error. This data can be displayed graphically over time.

Of particular interest in our programme has been the application of infrared thermography, both in the service and research programmes. The interest in thermography was drawn to the attention of our engineer by the work of Dr Paul Brand (1975) with respect to insensitive tissues. For the past eight months we have used thermography extensively, have assumed that the thermal response of the insensitive skin is proportional to the magnitude and duration of load upon the skin. We have found that colour thermograms give useful and immediate information as to tissues under excessive pressure. These pictures are stored in the central case registry for future comparative use. This information is then helpful in the 
decision toward redesigning of seats if need be. A thermogram can also be taken of our donned lower limb polypropylene orthoses which often cause excessive tissue sheer or pressure. Thermography is also an excellent educational medium for the young patients as they have no difficulty understanding that white and yellow areas on the monitor mean hot spots which they must avoid by existing or yet to be gained experience.

\section{RÉSUMÉ}

Dans un grand Centre de Rééducation, un travail d'équipe a été entrepris pour établir un protocole d'étude, contribuer aux soins et participer à la recherche de ce problème habituel et coûteux que sont les lésions cutanées.

Chez nos jeunes malades, le probleme le plus fréquent est secondaire à la position assise en fauteuil roulant.

Cet article décrit le programme envisagé et les efforts faits dans le sens de la recherche.

\section{ZUSAMMENFASSUNG}

In unserem grossen Zentrum für die Rehabilitierung von Kindern wurde ein Team zusammengestellt, dessen Aufgabe es ist, die Behandlung der häufigen und kostspieligen Gewebeschäden zu planen, die Behandlung auszuführen, und ausführlich zu studieren. In unseren jungen Patienten verursachte das Sitzen im Rollstuhl die häufigsten Gewebeschäden.

Dieser Bericht beschreibt das Behandlungs-Programm und die wissenschaftlichen Beobachtungen.

\section{REFERENCE}

BeRgtholdt, H. T. \& BRAND, P. W. (1975). Thermography: An aid in the management of insensitive feet and stumps. Archives of Physical Medicine and Rehabilitation, 56, 205. 